\title{
Micrografting Provides Evidence for Systemic Regulation of Sulfur Metabolism between Shoot and Root
}

\author{
Ilaria Forieri ${ }^{1}$, Rasha Aref ${ }^{1,2}\left(\mathbb{D}\right.$, Markus Wirtz ${ }^{1}(\mathbb{D})$ and Rüdiger Hell ${ }^{1, *(\mathbb{D}}$ \\ 1 Centre for Organismal Studies, University of Heidelberg, 69120 Heidelberg, Germany; \\ ilaria.forieri@gmail.com (I.F.); rasha_aref@agr.asu.edu.eg (R.A.); markus.wirtz@cos.uni-heidelberg.de (M.W.) \\ 2 Department of Genetics, Faculty of Agriculture, Ain Shams University, Cairo 11241, Egypt \\ * Correspondence: ruediger.hell@cos.uni-heidelberg.de; Tel.: +49-6221-54-5334
}

Citation: Forieri, I.; Aref, R.; Wirtz, M.; Hell, R. Micrografting Provides Evidence for Systemic Regulation of Sulfur Metabolism between Shoot and Root. Plants 2021, 10, 1729 https://doi.org/10.3390/ plants10081729

Academic Editor: Styliani (Stella) Chorianopoulou

Received: 22 July 2021

Accepted: 19 August 2021

Published: 20 August 2021

Publisher's Note: MDPI stays neutral with regard to jurisdictional claims in published maps and institutional affiliations.

Copyright: (c) 2021 by the authors. Licensee MDPI, Basel, Switzerland. This article is an open access article distributed under the terms and conditions of the Creative Commons Attribution (CC BY) license (https:// creativecommons.org/licenses/by/ $4.0 /)$.

\begin{abstract}
The uptake of sulfate by roots and its reductive assimilation mainly in the leaves are not only essential for plant growth and development but also for defense responses against biotic and abiotic stresses. The latter functions result in stimulus-induced fluctuations of sulfur demand at the cellular level. However, the maintenance and acclimation of sulfur homeostasis at local and systemic levels is not fully understood. Previous research mostly focused on signaling in response to external sulfate supply to roots. Here we apply micrografting of Arabidopsis wildtype knockdown sir1-1 mutant plants that suffer from an internally lowered reductive sulfur assimilation and a concomitant slow growth phenotype. Homografts of wildtype and sir1-1 confirm the hallmarks of non-grafted sir1-1 mutants, displaying substantial induction of sulfate transporter genes in roots and sulfate accumulation in shoots. Heterografts of wildtype scions and sir1-1 rootstocks and vice versa, respectively, demonstrate a dominant role of the shoot over the root with respect to sulfur-related gene expression, sulfate accumulation and organic sulfur metabolites, including the regulatory compound $\mathrm{O}$-acetylserine. The results provide evidence for demand-driven control of the shoot over the sulfate uptake system of roots under sulfur-sufficient conditions, allowing sulfur uptake and transport to the shoot for dynamic responses.
\end{abstract}

Keywords: organ communication; sulfur homeostasis; sulfate transporter; sulfite reductase; $O$-acetylserine; grafting

\section{Introduction}

Sulfur metabolism from sulfate uptake to the formation of organic sulfur compounds is present in all plants as part of their autotrophic lifestyle. The model plant Arabidopsis thaliana is by far the best investigated species with respect to primary and secondary sulfur metabolism [1,2]. Uptake of inorganic sulfate $\left(\mathrm{SO}_{4}{ }^{2-}\right)$ from the environment and its distribution throughout the plant is mediated by members of the sulfate transporter (SULTR) family [3]. The two genes encoding the plasmalemma localized high-affinity transporters SULTR1;1 and SULTR1;2 are almost exclusively expressed at the root surface. SULTR1 carries out the bulk of sulfate import, but the SULTR1;1 gene is stronger induced during external sulfate limitation and, therefore, often used as a marker of sulfur nutritional status [4]. Other members of the SULTR family are functioning in the translocation of sulfate from root to shoot (group 2), the import into plastids (group 3) and export from vacuoles (group 4) [4,5]. Importantly, the assimilatory reduction of sulfate takes place in plastids of photoautotrophic and heterotrophic plant cells. It is initiated by ATP sulfurylase (ATPS, EC 2.7.7.4), forming adenosine 5' - phosphosulfate. APS reductase (APR, EC 1.8.4.9) then uses two electrons from glutathione (GSH) to catalyze the reduction of APS to sulfite $\left(\mathrm{SO}_{3}{ }^{2-}\right)$. The latter is reduced to sulfide $\left(\mathrm{S}^{2-}\right)$ by sulfite reductase (SiR, EC 1.8.7.1), which receives six electrons from either photosynthesis (green cells) or the oxidative pentose phosphate pathway (white cells). In the final reaction sequence, sulfide is inserted into cysteine, which acts as a hub for the distribution of reduced sulfur into the many different 
downstream products, such as methionine and GSH [6]. With respect to regulatory steps in the pathway, the uptake of sulfate into the cell is a prerequisite, but APR underlies complex transcriptional and post-translational control mechanisms in response to many different environmental stresses and dominates flux control in the pathway [1,7]. Interestingly, the step catalyzed by SiR is much less regulated but gains substantial control under sulfur starvation conditions [8]. Moreover, $\mathrm{SiR}$ is encoded by the only single-copy gene in sulfate assimilation of Arabidopsis [9], making this step a valuable tool for the investigation of primary sulfur metabolism [10-12].

Thus, nearly all cells of a plant possess the ability to assimilate sulfate, and accordingly, the respective organs show at least a partial autonomy with respect to assimilatory sulfate reduction. However, the bulk of sulfate is believed to be reduced by electrons from photosynthesis in leaves $[1,2,13]$, implying the transport of sulfur is reduced by photosynthesis from shoot to the root.

Here, the question of the systemic interaction of the shoots and roots with respect to the metabolic and transcriptomic remodeling under internal sulfur limitation was addressed. The typical response to sulfate deficiency in the soil in most plants consists in an early upregulation of Sultr1;1 and subsequently of many other genes [14,15]. Prolonged starvation results in chlorosis of older leaves and acclimatory differentiation of the root system [2]. How the shoots and roots communicate with respect to sulfate assimilation and growth control is largely unknown. In contrast to the well-investigated external depletion of sulfate, a grafting approach between Arabidopsis root and the shoot of wildtype and the sir1-1 mutant was applied. The T-DNA insertion in the sir1-1 mutant is located in the promoter region, causing lowered expression of the SiR gene and SiR protein. This causes a severe limitation of reduced sulfur for biosynthetic pathways and results in the constitutive up-regulation of root Sultr1;1 expression and accumulation of sulfate in leaves [10-12]. This de-regulation of sulfur metabolism gives rise to a strong and easy-to-score growth retardation of the shoots and roots [12]. The mutant sir1-2 is also a promoter insertion mutant, with $14 \%$ SiR transcript levels left compared to the wildtype and is seedling lethal in homozygote plants. In contrast, sir 1-1 has around $23 \% \mathrm{SiR}$ transcript levels in mature leaves, concomitantly lowered SiR protein and enzyme activity levels and accordingly lowered levels in roots compared to the wildtype [11,12]. The somewhat weaker alleles sir1-3 and sir1-4 are also slightly growth retarded and have been shown to be sensitive to $\mathrm{SO}_{2}$ stress, pointing to further important functions of $\mathrm{SiR}$ in plants $[16,17]$.

Thus, the sir1-1 mutant has an intrinsic deficiency for reduced sulfur, making it the ideal complement to the external sulfate deficiency experiments for the investigation of systemic regulation of sulfur metabolism. The shoot or root was combined with the corresponding wildtype organ using micrografting to generate homo and heteromeric chimeric plants. The results demonstrate that the disruption of shoot sulfur assimilation is able to influence the regulation of sulfate uptake at the root level, the composition of primary sulfur compounds and root growth, but not vice versa. Thus, the grafting approach is a suitable tool to address systemic relationships and indicates that the shoot is in command of the autonomous sites of sulfur metabolism when external sulfur supply is not limiting.

\section{Results}

\subsection{Phenotypical Analysis of Micrografted Wildtype and sir1-1 Arabidopsis Plants}

Micrografting was performed with 6-7-day-old wildtype (WT) and sir1-1 seedlings to obtain chimeric plants (heterografts) that had the shoot of one genotype and the root of the other: WT shoot/sir1-1 root (WT/sir1-1) and sir1-1 shoot/WT root. As controls, homografts were included in each grafting experiment: WT shoot/WT root (WT/WT) and sir1-1 shoot/sir1-1 root (sir1-1/sir1-1). Grafted plants were harvested at the end of the fifth week after seed germination, and the fresh weight of rosette and roots were determined prior to gene expression and metabolite analyses. The results are modified from the data shown in [11]. The control homografts of WT/WT and sir1-1/sir1-1 successfully 
reproduced the morphology and SiR depletion-induced slower growth that is observed for sir1-1 lines grown in soil [12] (Figure 1a). The sir1-1/sir1-1 plants were significantly smaller compared to WT/WT plants and accordingly had reduced fresh weights of roots (2-fold) and shoots (1.6-fold) (Figure 1c,d). The heterografts resulted in distinct phenotypes (Figure 1b): the WT/sir1-1 combination showed a WT-like phenotype in the shoot and also in the root, whereas the sir1-1/WT combination resulted in plants that had sir1-1-like shoots and also roots. The phenotype of these heterografts was reflected by the measured fresh weights of both roots and shoot (Figure 1c,d). In fact, the WT/sir1-1 combination showed no measurable difference in the fresh weight of both roots and shoots compared to the WT/WT homografts. The sir1-1/WT combination instead showed a significant decrease in the fresh weight of both roots and shoot (1.9-fold and 1.8-fold, respectively).

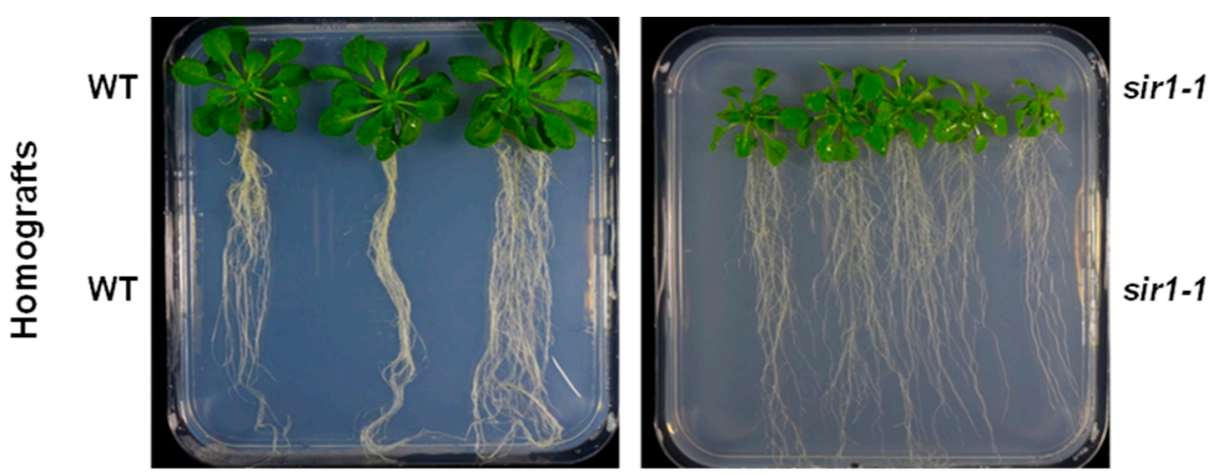

(a)
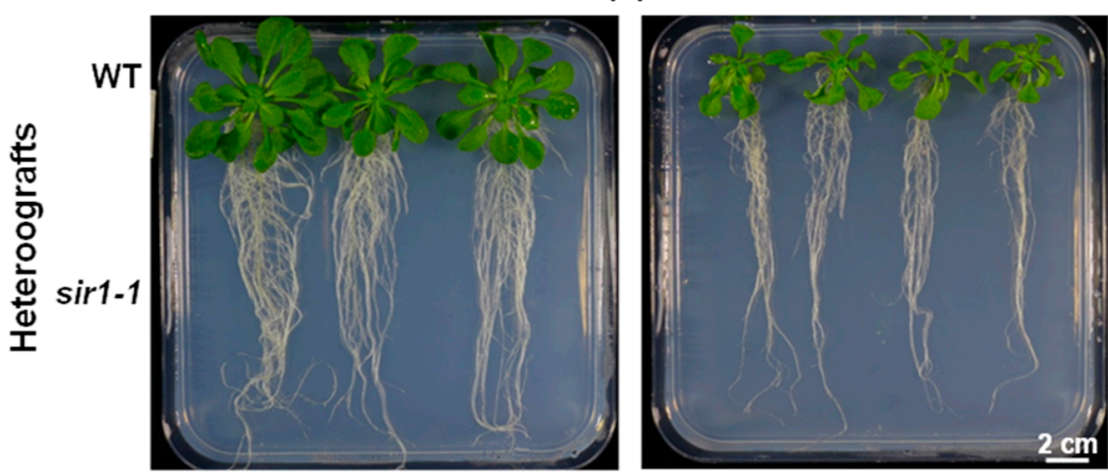

$\operatorname{sir} 1-1$

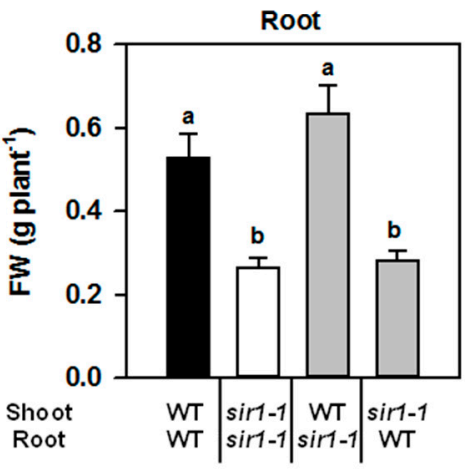

(c) (b)

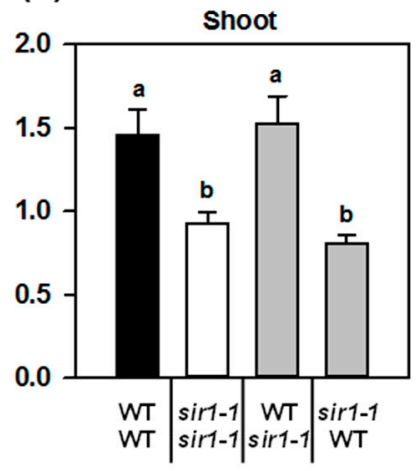

(d)

Figure 1. Phenotypic analysis of micrografted plants. (a,b) Phenotype of grafted plants five weeks after germination; selected representatives are shown for the four different grafting combinations. (c,d) Fresh weight (FW) of roots and shoots. Data represent mean and standard error and are modified according to [11] $(n>15)$. Different letters indicate statistically significant differences; $p<0.05$, ANOVA followed by Dunn's test; FW = fresh weight. 
From the phenotypic analysis of reciprocal sir1-1 graftings, it is evident that the shoot imposes the growth phenotype to the root as shown previously [11]. However, it was unknown if this growth phenotype is exclusively a consequence of depleted SiR activity in shoots or also caused by misbalanced organ-organ communication via shoot-derived long distancing signaling. To address the potential impact of impaired shoot-sulfur reduction capacity on the S-uptake capacity/S-metabolism of the root, we determined steady-state transcript levels and key metabolites of the S-assimilation pathway in both organs of the homografts or heterografts of wildtype and sir1-1.

\subsection{SiR, APR2 and SULTR1;1 Transcripts Are Differentially Expressed in Micrografted Plants}

The location of the T-DNA in the promotor region of the sir1-1 allele causes different degrees of reduction of SiR1 mRNA levels in different organs. Mature leaves and roots of the sir1-1 mutant display an up to a 4-fold decrease in SiR transcript amount [11,12]. The micrografted plantlets very much reflected this differential expression pattern, confirming the suitability of the approach: in the roots of sir1-1/sir1-1 homografts, SiR mRNA level was down to $60 \%$ and in the shoot, down to $30 \%$ compared to the WT/WT homografts (Figure 2a). Remarkably, in WT/sir1-1 heterograft roots, the SiR expression was found to be decreased only by about $15 \%$ compared to the WT/WT combination, while in the roots of sir1-1/WT, the SiR mRNA level was decreased to the same extent as in sir1-1/sir1-1 roots. This means that (1) the WT scion nearly reconstituted SiR expression in sir1-1 root and (2) the sir1-1 scion led to lowered SiR expression in WT root, indicating control from the shoot to the root. In contrast, the shoot SiR expression in the sir1-1/sir1-1 autografts (Figure 2b) was downregulated 3.1-fold and unchanged in the WT/sir1-1 graft combination while it was 4.2-fold down-regulated in the sir1-1/WT combination, excluding an effect on SiR expression from the root to the shoot.

The key regulated step in sulfate reduction during external sulfate deficiency is encoded by APR2, the major one of the three APR isoforms in Arabidopsis [18]. Depletion of SiR activity in the shoots of seven-week-old sir1-1 plants compared to WT resulted in feedback inhibition of the APR2 gene, while APR1 and APR3 transcription were unaffected [12]. However, in roots of hydroponically grown sir1-1, all APR isoforms were induced, suggesting that this APR2 feedback inhibition might be controlled in an organspecific manner [11]. Thus, the APR2 transcript level was measured in both the roots and shoots of micrografted plants to assess whether the different tissues have an impact on the regulation of the response to constitutive internal sulfur deficiency (Figure 2b).

$A P R 2$ expression was upregulated 1.2-fold in the roots of sir1-1/sir1-1 homografts compared to the WT/WT plants, whereas it was unchanged in the roots of the two heterograft combinations (Figure 2c). These findings demonstrate that APR2 expression was not a subject of SiR depletion-induced feedback inhibition in roots, no matter if SiR was depleted in the shoot or the root itself. The APR2 steady-state transcript levels in the shoot of sir1-1/WT and sir1-1/sir1-1 were decreased to $60 \%$ of the wildtype level, which confirmed the previously shown APR2 feedback inhibition in the shoots of soil-grown sir1-1 [12]. These results suggest that the APR2 feedback inhibition is a direct consequence of decreased SiR activity in the shoot and is restricted to the shoot (see above). Surprisingly, grafting of a sir1-1 root to the WT shoot also caused substantial depletion of APR2 transcript (Figure 2d, WT/sir1-1), albeit these plants grew similar to the wildtype (Figure 1). 


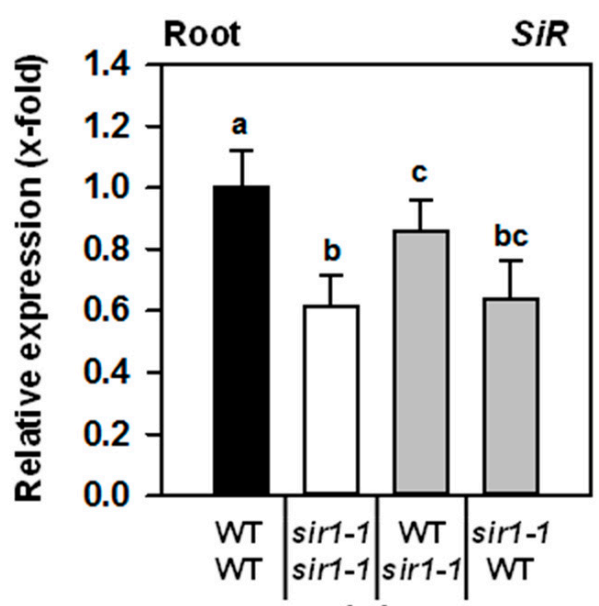

(a)

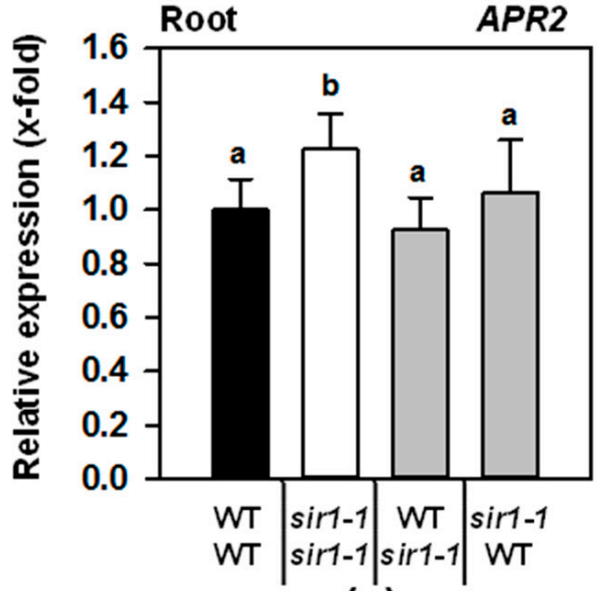

(c)

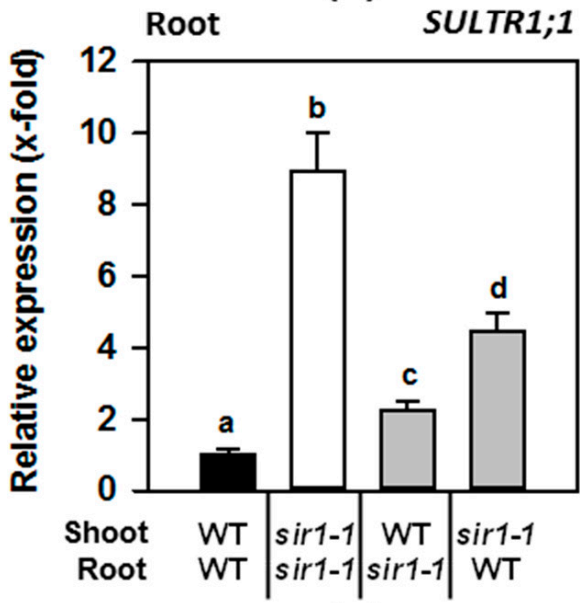

(e)

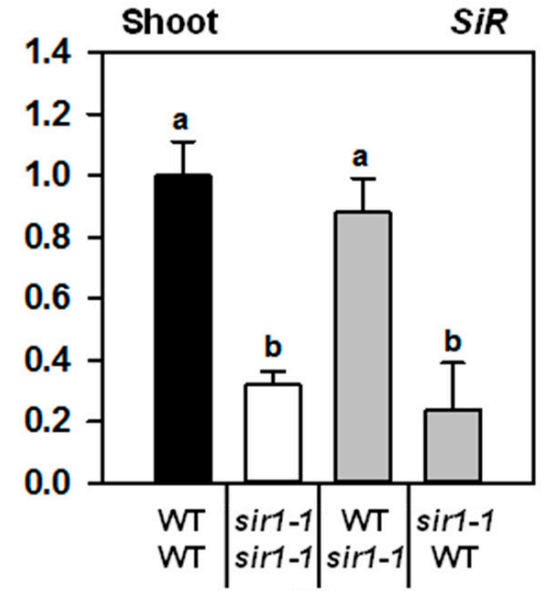

(b)

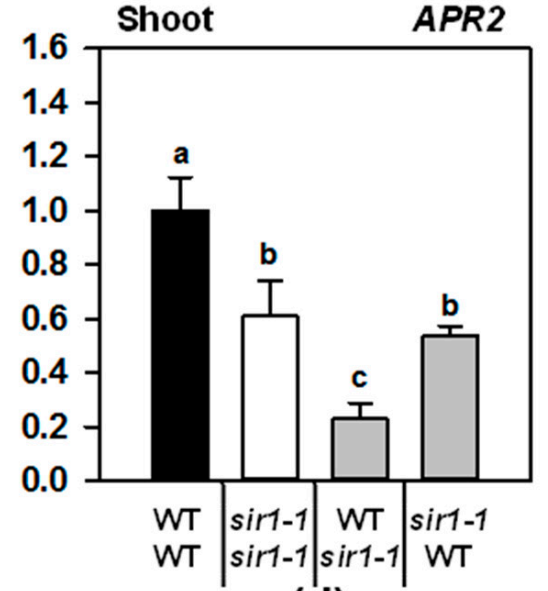

(d)

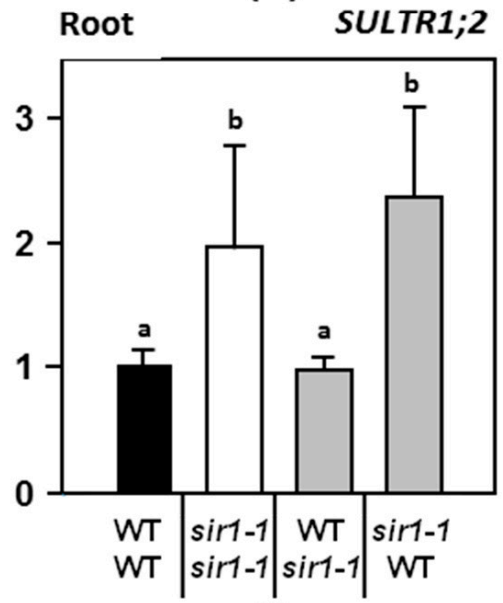

(f)

Figure 2. Steady-state transcript levels of key genes in the sulfur-assimilation pathway in micrografted plants. Transcript levels were determined by qRT-PCR using TIP41-like (At4g34270) as the reference gene in the roots $(\mathbf{a}, \mathbf{c}, \mathbf{e}, \mathbf{f})$ and shoots $(\mathbf{b}, \mathbf{d})$ of grafted plants. The level in control roots and shoots was set to 1 , and the other values are expressed as x-fold of control. Data are shown as means \pm SE $(n=4)$. Different letters indicate individual groups identified by multiple pairwise comparisons with a Holm-Sidak, one-way ANOVA $(p, 0.05)$ followed by the Student-Newman-Keuls posthoc test. 
One of the peculiarities of the T-DNA insertional mutant sir1-1 is a constitutively enhanced expression of the high-affinity sulfate transporter gene SULTR1;1 in roots of up to 10-fold [10], which results in increased sulfate accumulation in the shoot compared to the wildtype [10,12]. The homografts sir1-1/sir1-1 indeed showed an 8.9-fold upregulation of SULTR1;1 expression (Figure 2e). The WT/sir1-1 grafting combination and the sir1-1/WT combination up-regulated SULTR1;1 transcript level 2.2-fold and 4.4-fold, respectively. Analysis of the bulk uptake system encoded by SULTR1;2 showed a similar pattern with enhanced expression in sir1-1/sir1-1 and sir1-1/WT grafts, albeit at a lower level (Figure 2f). These results further support the hypothesis that deregulated sulfate assimilation in the shoot can influence the regulation of sulfate uptake and assimilation in the roots.

\subsection{Shoot-Specific De-Regulation of Sulfate Assimilation Causes Specific Adaption of Major Nutrients in Root and Shoot of Micrografted Plants}

The sir1-1 mutant plants show altered sulfate concentrations in the shoot compared to WT and simultaneously a disturbed nitrogen metabolism with a significant decrease of nitrate and of reduced nitrogen-containing compounds [12]. Sulfate and nitrate were quantified in micrografted plants together with phosphate to further dissect the differential contribution of root and shoot in the regulation of the responses to intrinsic sulfur starvation (Figure 3).

Indeed, sir1-1/sir1-1 plants confirmed the substantial accumulation of sulfate in the shoots of soil-grown sir1-1 plants. This increase also occurred when SIR activity was depleted in shoots of sir1-1/WT grafts. However, the decrease of SiR in the roots of WT/sir1-1 did not result in sulfate accumulation in the scion when compared to WT/WT (Figure $3 \mathrm{~b}$ ). The shoot-specific accumulation of sulfate correlated with the induction of the high-affinity sulfate uptake systems in roots if the scion had a sir1-1- background (Figure 2e,f).

Surprisingly, the depletion of SiR activity in the roots and the shoots (sir1-1/sir1-1) had no significant impact on the steady-state levels of sulfate, phosphate or nitrate in the root. Consequently, also in the roots of heterografted plants, sulfate, phosphate and nitrate concentrations remained unaltered (Figure $3 \mathrm{a}, \mathrm{c}, \mathrm{e}$ ). Phosphate was not significantly affected in the shoot or root of any grafting combination (Figure 4d), suggesting that the grafting procedure had no general effect on anion uptake. Nitrate concentrations in shoots again mirrored the levels observed in ungrafted plants [12] and showed the opposite pattern compared to sulfate: it was significantly decreased in the shoot of sir1-1/sir1-1 and sir1-1/WT plants (1.8-fold and 1.2-fold, respectively) and unchanged in the WT/sir1-1 shoot (Figure 4f).

Thus, the anion concentration pattern in the organs of micrografted plants appears to be strictly dependent on the shoot genetic background, with the specific accumulation of sulfate and decreased nitrate in the shoots of sir1-1 background. On the contrary, the depletion of sulfur reduction in the roots of WT/sir1-1 or sir1-1/sir1-1 has no significant influence on macronutrient accumulation in the shoot. 


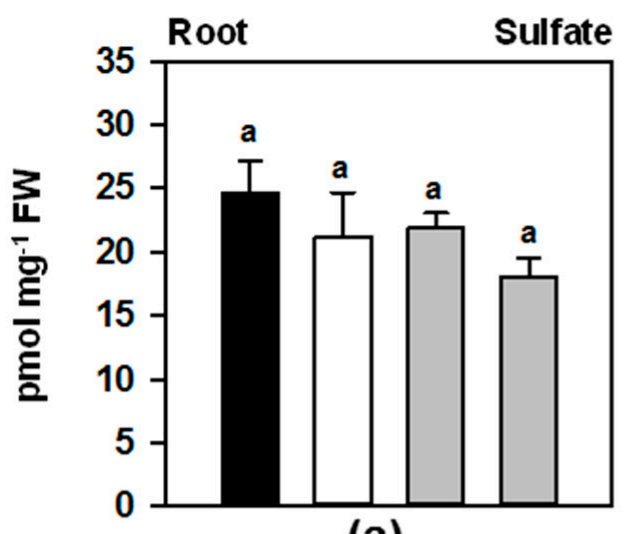

(a)

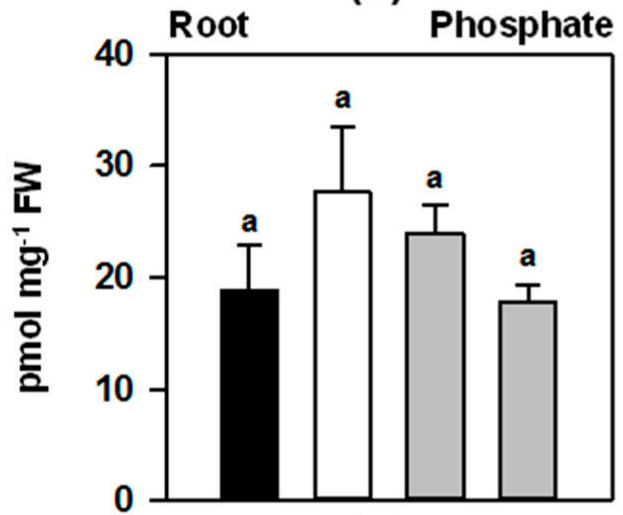

(c)

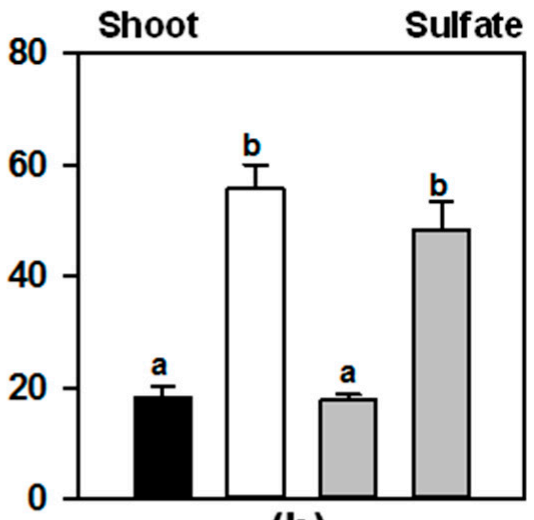

(b)

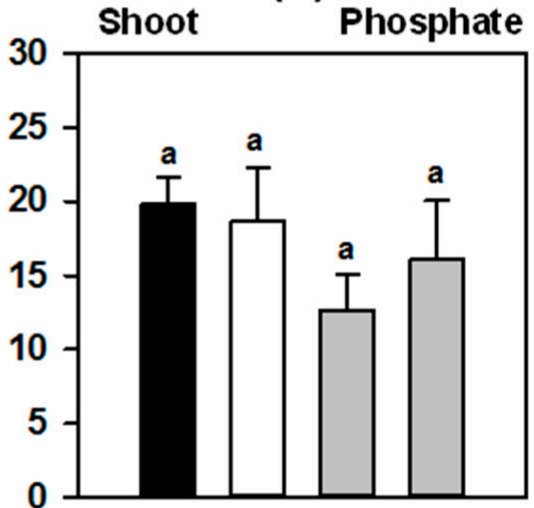

(d)

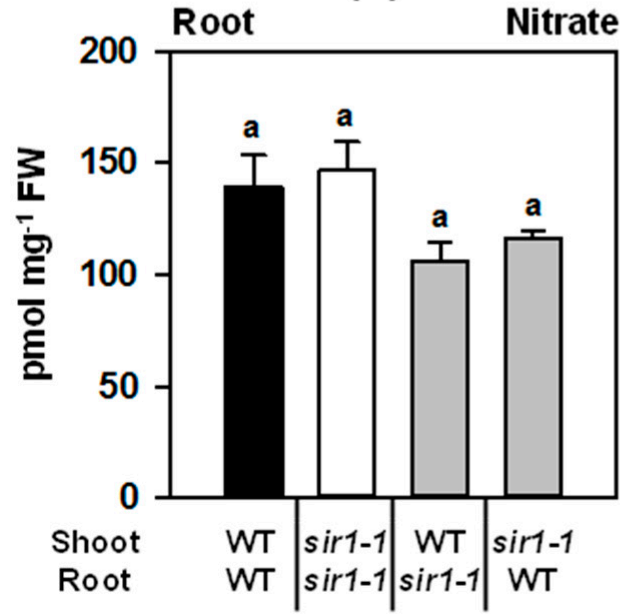

(e)

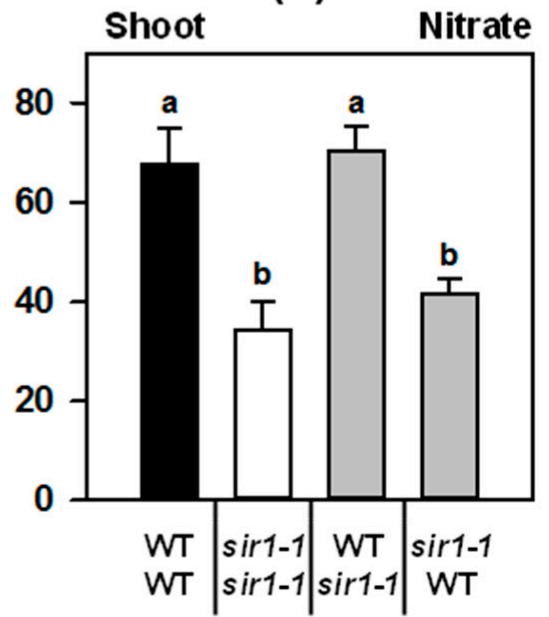

(f)

Figure 3. Steady-state levels of macronutrients in the roots and shoots of micrografted plants. Sulfate $(\mathbf{a}, \mathbf{b})$, phosphate $(\mathbf{c}, \mathbf{d})$ and nitrate $(\mathbf{e}, \mathbf{f})$ concentrations in roots $(\mathbf{a}, \mathbf{c}, \mathbf{e})$ and shoots $(\mathbf{b}, \mathbf{d}, \mathbf{f})$ of micrografted Arabidopsis plants. Data represent the means \pm SE $(n=4)$. Different letters indicate individual groups identified by multiple pairwise comparisons with a Holm-Sidak, one-way ANOVA $(p, 0.05)$ followed by the Student-Newman-Keuls posthoc test. 


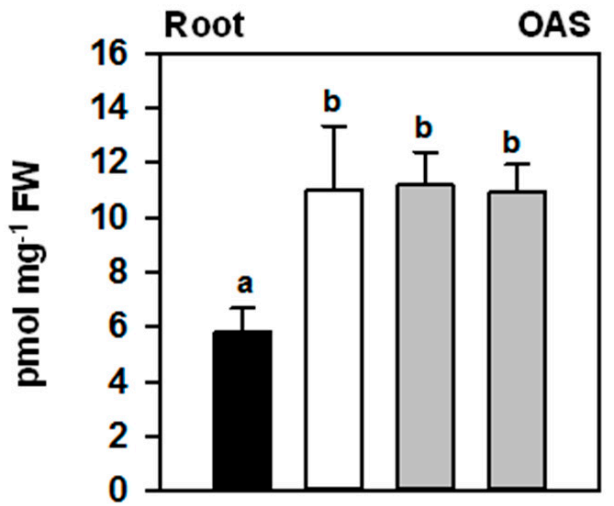

(a)

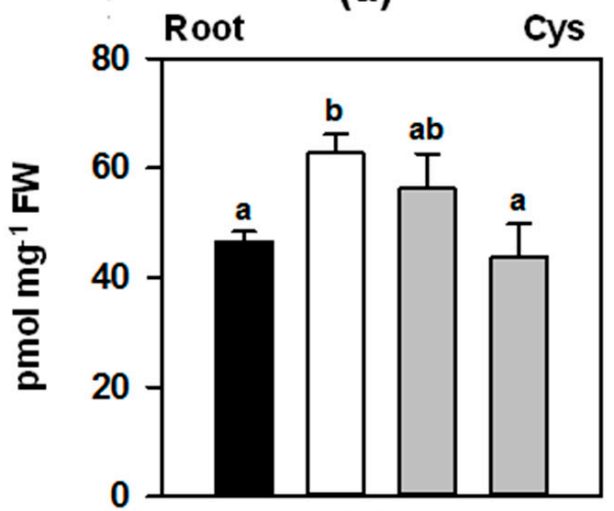

(c)

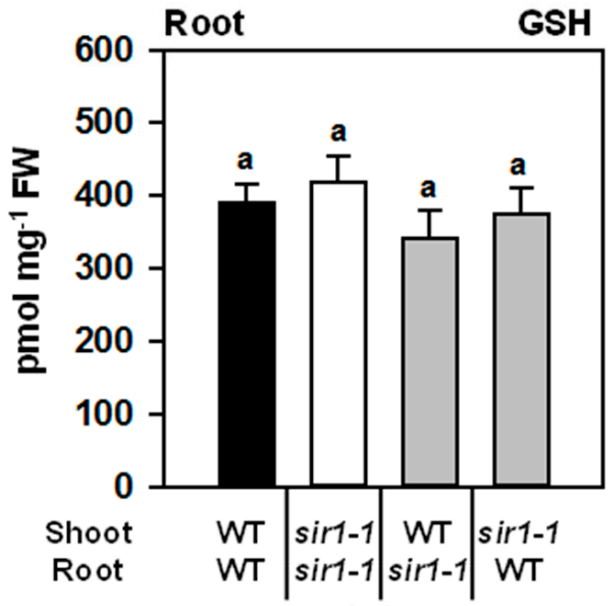

(e)

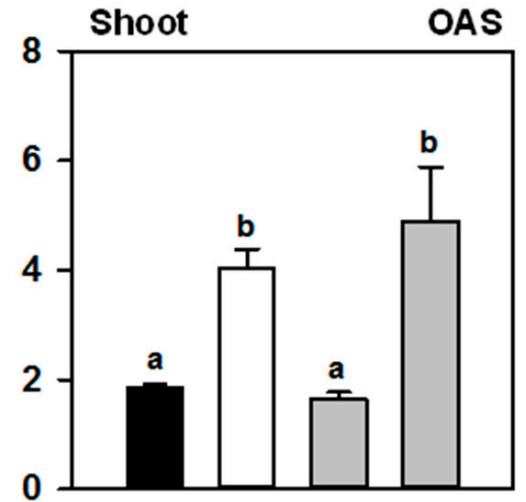

(b)

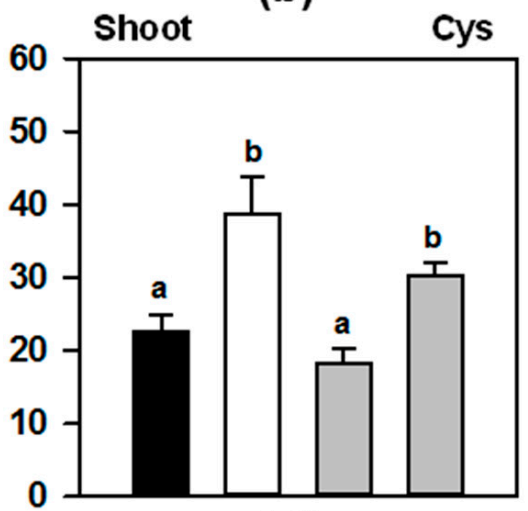

(d)

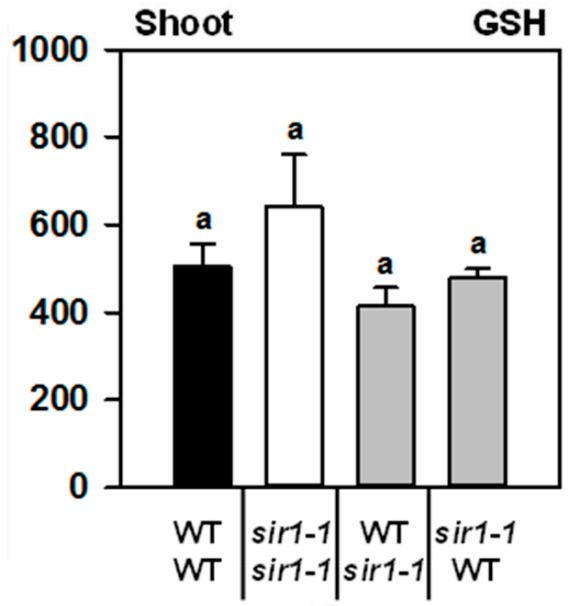

(f)

Figure 4. Steady-state levels of OAS and thiols in micrografted plants. Concentrations of OAS (a,b), Cys $(\mathbf{c}, \mathbf{d})$ and GSH $(\mathbf{e}, \mathbf{f})$ in roots $(\mathbf{a}, \mathbf{c}, \mathbf{e})$ and shoots $(\mathbf{b}, \mathbf{d}, \mathbf{f})$. Data represent the means \pm SE $(n=4)$. Different letters indicate individual groups identified by multiple pairwise comparisons with a Holm-Sidak, one-way ANOVA $(p, 0.05)$ followed by the Student-Newman-Keuls posthoc test.

\subsection{OAS and Thiols in the Grafted Plants}

The cysteine precursor $O$-acetylserine (OAS) is intensively discussed as a signal for the expression of many genes related to sulfur metabolism [15]. The sir1-1 mutant is characterized by an increased OAS concentration due to the limited flux into cysteine and also an impact on the thiol steady-state level [12]. OAS was found to be increased in the roots of all the grafting combinations (1.9-fold) compared to the WT/WT homografts (Figure 4a). In the shoot, OAS was 2.2-fold accumulated in sir1-1/sir1-1 homografts, thus well reflecting the situation in soil-grown non-grafted sir1-1 mutant plants [12]. It was 
unchanged in the WT/sir1-1 combination and accumulated 2.6-fold in the sir1-1/WT combination (Figure 4b). Thus, the sir1-1 mutation caused the shoot to accumulate OAS even when grafted on a WT root.

The steady-state abundance of cysteine (Cys) largely mirrored the OAS pattern even though Cys concentrations in sir1-1/sir1-1 grafts were not significantly enhanced. The observed 1.7-fold and 1.3-fold increased Cys concentrations in the shoot of sir1-1/sir1-1 and sir1-1/WT grafts, respectively, supported the dominating role of the shoot over the root. GSH concentrations were about 10-fold higher compared to Cys levels as could be expected from the analyses of intact plants (see [6], for review). They remained constant within statistical variation in the roots (Figure 4e) and in the shoots (Figure 4f) of all tested grafting combinations.

The quantification of metabolites in the four grafted genotypes allows us to conclude that the depletion of $S i R$ gene expression was the primary reason for the specific adaptations of the sulfur and, also to some extent, nitrogen metabolism in the sir1-1 plant. However, this perturbation of nitrogen metabolism is unlikely to contribute to the observed retarded growth of sir-1-1, since (1) total nitrogen content of sir1-1 is only decreased by $10 \%$, (2) nitrogen-containing biomolecules accumulate in sir1-1 and (3) the sir1-1 phenotype can be suppressed by redirecting sulfur-flux from glutathione biosynthesis to cysteine biosynthesis $[10,12]$. Our findings demonstrate a substantial demand-driven control of nutrient uptake by the roots for supply to the shoot.

\section{Discussion}

Grafting is a well-established method in horticulture for the improvement of woody plants, such as grapevine and apple. Suitable combinations of scion and rootstock can lead to improved plant growth and yield under abiotic and biotic stress [19]. Chimeric plants have been applied to investigate the long-distance transport of large and small molecules via the xylem and the phloem. Remarkably, grafting also contributed to the identification of CEPD1/2 proteins that are shoot-to-root mobile proteins, transmitting the systemic $\mathrm{N}$-deficiency signal. The shoot-specific expression of CEPD1/2 is induced by the root-toshoot mobile peptide hormone, C-TERMINALLY ENCODED PEPTIDE (CEP), originating from the N-starved roots. This example of antagonistically transported but entailing signals unravels the complexity of organ communication that is critical for coordinating soil-borne nutrient uptake [20]. Such nutrient-deficiency induced long-distance signals include not only peptide hormones and proteins but also nutrients themselves, sugars, hormones, silencing and messenger RNAs (reviewed in [21,22]). Earlier experiments using non-grafting approaches had revealed that sulfur metabolism-related compounds could have long-distance signaling functions. The vascular-transported sulfate for the closing of stomata during early drought stress is one such example [23-25], but also phloemmediated transport of miRNA395 mainly regulating Sultr2;1 and APR2 gene expression in roots [26,27], and the source to sink transport of GSH and S-methylmethionine in the phloem may have control functions beyond sulfur supply [28,29]. S-nitrosoglutathione is another sulfur-containing compound that has been suggested to be involved in shoot-toroot communication due to organ-specific dynamic inactivation by S-nitrosoglutathione reductase (GSNOR) [30]. GSNOR rapidly degrades S-nitrosoglutathione and controls the demethylation and expression of transposable elements and stress-responsive genes [31]. Remarkably, DNA demethylation of the SULTR1;1 promotor also triggers the expression of SULTR1;1 and is responsive to external sulfur supply [32]. GSNOR is particularly important for controlling Fe-metabolism [30]; Fe metabolism is known to be tightly co-regulated with sulfur availability since most of the bound iron is incorporated in iron-sulfur clusters of diverse protein, including SiR (reviewed in [33] and discussion of [34]).

Investigations in Brassica oleracea showed that prolonged sulfate starvation led to an increased biomass ratio of root to shoot but revealed limited shoot to root signaling with respect to the expression of sulfate transporters [35]. Thus far, grafting has not been applied to investigate root-shoot relationships in sulfur metabolism but split root experiments indi- 
cated extensive communication between well-supplied and sulfate starved roots, possibly via the shoot, with respect to sulfate, OAS and GSH as signaling molecules [36-38].

A split-root approach with Brassica napus and external sulfate deficiency $[36,39,40]$ showed a demand-driven control of sulfate acquisition and assimilation and identified GSH as the likely phloem-translocated signal from the shoot to the root to integrate the nutritional status of the leaves. A similar approach revealed both local and systemic regulation of sulfur-related gene expression with OAS and sulfate itself as major signal components [38]. Using radiolabeled sulfate, the authors found that sulfate is by far the dominating mobile sulfur compound between shoots and roots. In the derived model, local sulfate supply regulates the expression of the Sultr 1;1 and Sultr2;1 genes in the root, and the sulfur status in the shoot modulates the OAS-mediated gene expression response by a 'passive sulfur status-dependent' transport of sulfate.

The main differences between the grafting approach applied here, and these split root systems are that local and external deficiencies of inorganic sulfate formed the trigger of transport and responses in the plant. In contrast, the chimeric plants with sir1-1 genetic background displayed an organ-restricted limitation of reduced sulfur, thus providing a novel view on the communication between shoots and roots.

The grafting of the sir1-1 shoot to the wildtype root was sufficient to induce the root plasma membrane-resident high-affinity sulfate uptake system in the presence of external sulfate. This finding provides direct evidence for a demand-driven control of sulfate uptake to optimize sulfate movements between the sink and source organs. Such a demand-driven regulation was postulated for a long time [41]. However, the demand-driven control hypothesis was challenged by the finding that local induction of the root-sulfate uptake system by external sulfur-deprivation was not reverted in plants fed via the leaves with atmospheric sulfide [35]. This earlier study clearly demonstrated that the roots perceive the local sulfur supply and react to this limitation with an induction of the sulfate uptake capacity irrespective of the sulfur supply of the shoot. The here demonstrated shoot demand-driven control is not contradicting this previous conclusion but adds a novel layer of complexity to the maintenance of whole plant sulfur homeostasis when external sulfur is not limiting.

The shoot demand-driven induction of the root sulfate uptake system did not correlate with locally enhanced steady-state levels of previously identified sulfur-starvation signals (Figure 4). However, this result does not exclude the signaling role of these compounds since we are missing information about the subcellular distribution of these signals. Furthermore, some of these signals might be perceived as ratios with additional specifiers. In the case of OAS, a potential sensor would be the OAS-dissociable cysteine synthase complex, consisting of serine acetyltransferase and OAS(thiol)lyase, which can bind OAS and sulfide and is subject to extensive protein modifications [42,43]. Remarkably, OASinduced dissociation of the CSC is counteracted by sulfide [44]. The recent identification of the ASTOL1 point mutation in the OAS-binding component of the CSC uncovered the pivotal sensing function of the plastid-localized CSC and its importance for optimizing the stress resilience of plants [45]. However, the CSC also operates in the cytosol and the mitochondria as an OAS-sensor $[46,47]$. Furthermore, sulfide has been shown to act as a mobile gaseous signal, controlling diverse aspects of plant metabolism [48-50]. The concept of transceptors, which are defined as metabolite transporters acting as receptors, would allow the sensing of shoot-to-root transport of sulfur-demand signals without the necessity of substantial fluctuations in steady-state metabolite levels [51]. In this respect, it should be noted that plants SULTR possess a STAS domain that is supposed to have a regulatory function and allows for the physical interaction of membrane-resident SULTRs with OAS-TL $[52,53]$. The absent correlation of SULTR1;1 and SULTR1;2 transcriptions in roots with neither OAS, sulfate, or glutathione steady-state levels was observed earlier [54]. In this study, roots were submitted to a wide diversity of experimental conditions, which uncovered that SULTR1;2 transcriptions correlated better with the metabolic demand of the 
shoot and the photoperiod, while the SULTR1;1 gene predominantly but not exclusively, reacted to the local sulfur supply at the rhizosphere.

\section{Materials and Methods}

\subsection{Plant Genotypes and Growth Conditions}

Arabidopsis thaliana mutant plant (sir1-1) and wildtype control plants were in the Columbia (Col-0) ecotype. The T-DNA insertion line sir1-1 was described and verified for homozygosity of the corresponding T-DNA insertion with primers according to [12]. Plants were grown in a growth cabinet with an $8 \mathrm{~h} / 16 \mathrm{~h}$ day /night cycle at a light intensity of $120 \mu \mathrm{mol} \mathrm{m}{ }^{-2} \mathrm{~s}^{-1}$ and 22 and $18^{\circ} \mathrm{C}$, respectively.

\subsection{Grafting}

The grafting of Arabidopsis using silicon tubes followed the method described in [55]. Seedlings were grown on plates containing sterile $1 / 4$ MS media with $1 \%$ sucrose and $1.4 \%$ agar. The medium was supplemented with $40 \mathrm{mg} / \mathrm{L}$ ampicillin to inhibit bacteria growth. Seeds were surface sterilized with $1 \mathrm{~mL} \mathrm{70 \%} \mathrm{(v/v)} \mathrm{ethanol} \mathrm{and} 0.01 \%$ Triton X-100 for 20-30 min, then washed at least five times with $\mathrm{ddH}_{2} \mathrm{O}$ and transferred onto plates using a pipette. The grafting was performed 7-8 days after placing the plates vertically into the growth cabinet. Seedlings were cut using a razor blade not lower than midway down the hypocotyls. Shoot and rootstocks were separated and a silicon tube (diameter $0.3 \mathrm{~mm}$, opened using a razor blade and cut in small pieces about 2-3 $\mathrm{mm}$ long) was slid over the rootstock. Afterward, the scion was pushed into the tube until it reached contact with the rootstock. The grafted plantlets were placed on a new plate containing fresh media and returned to the growth cabinet. Three to four days after grafting, plantlets were inspected for adventitious root formation on the scion. Those roots were removed by cutting them with a razor blade. Successfully grafted plants were maintained for five weeks in the same growth conditions; after 2.5 weeks, they were moved to a fresh plate. At the end of the 5 th week, the shoots and roots were harvested separately using different razor blades and forceps in order to avoid contaminations. The genetic identity of wildtype and sir1-1 scions and rootstocks after grafting was verified by genomic PCR, as shown in [11].

\subsection{RNA Extraction and Transcript Levels Analyses}

Total RNA was extracted from $50 \mathrm{mg}$ of frozen root material using the peqGOLD Total RNA Kit (peqGOLD, Erlangen, Germany) according to the manufacturer's instructions. Reverse transcription quantitative PCR (RT-qPCR) analysis was performed using the qPCRBIOSyGreen Mix Lo-ROX (PCR Biosystems) in the Rotor-Gene Q cycler (Qiagen, Hilden, Germany). Gene-specific primers used for RT-qPCR: APR2_for CCCGTTCACTTTAGCATCATCGGAG; APR2_rev GATCGAACCCATTTGTCTCAGAGAC; SULTR1;1_for GCCATCACAATCGC TCTCCAA; SULTR1;1_rev TTGCCAATTCCACCCATGC; SULTR1;2_for GGATCCAGAGATGGCTACATGA; SULTR1;2_rev TCGATGTCCGTAACAGGTGAC; TIP41-like_for GATGAGGCACCAACTGTTCTTCGTG; TIP41-like_rev CTGACTGATGGAGCTCGGGTCG; SiR_for TTGAAAAGGTTGGTCTGGACTAC; SiR_rev GGTGTTCCTCCTAGCCAAAC.

\subsection{Metabolite Analyses}

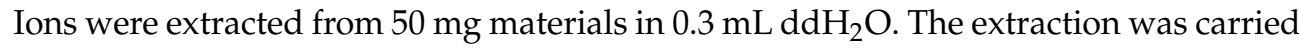
out at $98^{\circ} \mathrm{C}$ for $30 \mathrm{~min}$ under constant shaking. The aqueous extracts were diluted three times with $\mathrm{ddH}_{2} \mathrm{O}$ to a final volume of $300 \mu \mathrm{L}$ and transferred to HPLC vials. The determination was carried out on an ICS-3000 system (Dionex) with an IonPac AS 11 column and $15-300 \mathrm{mM} \mathrm{NaOH}$ (Fluka, Buchs, Switzerland, in $\mathrm{ddH}_{2} \mathrm{O}$ ) as eluent. Amperometric detection allows quantitative calculation of the organic acids and inorganic ions and was performed using Chromeleon software 6.7 (Dionex, Germany). ${ }^{\circ} \mathrm{C}$. For the measurement of thiols and OAS, total metabolites were extracted from $50 \mathrm{mg}$ leaf or root materials with $0.5 \mathrm{~mL} 0.1 \mathrm{M} \mathrm{HCl}$. The determination of OAS was based on the derivatization with the 
fluorescent dye AccQ-TagTM. An aliquot of $10 \mu \mathrm{L} \mathrm{HCl} \mathrm{extracts} \mathrm{was} \mathrm{mixed} \mathrm{with} 70 \mu \mathrm{L}$ borate buffer $(0.2 \mathrm{M}, \mathrm{pH} 8.8)$ and $20 \mu \mathrm{L} 3 \mathrm{mg} \mathrm{ml}^{-1}$ AccQ-TagTM solution. The derivatization was performed at $55^{\circ} \mathrm{C}$ for $10 \mathrm{~min}$. The data were analyzed using the software Empower Pro. To detect thiols, $25 \mu \mathrm{L} \mathrm{HCl}$ extracts were incubated with $245 \mu \mathrm{L}$ reduction buffer (68 mM Tris, $\mathrm{pH} 8.3$; $0.34 \mathrm{mM}$ DTT; $25 \mu \mathrm{L} 0.08 \mathrm{M} \mathrm{NaOH}$ ) for $1 \mathrm{~h}$ at room temperature in the dark. The reduced thiol groups were derivatized with $0.85 \mathrm{mM}$ of the fluorescent dye monobromobimane at room temperature for $15 \mathrm{~min}$ in the dark. An aliquot of $705 \mu \mathrm{L} 5 \%$ acetic acid was used to stop the derivatization. The separation of thiols was performed by reversed-phase HPLC on a Nova-PakTM C18, $4.6 \times 250 \mathrm{~mm}$ column as described in [56]. Thiol-bimane derivatives were detected at an emission wavelength of $480 \mathrm{~nm}$ upon excitation at $380 \mathrm{~nm}$.

\subsection{Statistical Analyses}

Statistical analysis was performed using the software suite SigmaPlot 12.5 (Systat). Different letters indicate individual groups identified by multiple pairwise comparisons with a Holm-Sidak, one-way ANOVA $(p, 0.05)$ followed by the Dunn's or the StudentNewman-Keuls posthoc test.

Author Contributions: Conceptualization, M.W. and R.H.; validation, I.F. and R.A.; investigation, I.F.; writing—original draft preparation, R.A. and R.H.; writing—review and editing, R.A., M.W. and R.H.; supervision, M.W. and R.H.; funding acquisition, M.W. and R.H. All authors have read and agreed to the published version of the manuscript.

Funding: This research was funded by the German Science Foundation (DFG), grants no. He 1848/15-2, WI 3560/1-2, Excellence Cluster CellNetworks EcTop6.

Acknowledgments: The authors wish to thank the Metabolomics Core Technology Platform Heidelberg for support with the analyses of plant metabolites. We are grateful to Richard Kragler and his team (Max-Planck Institute for Molecular Plant Physiology, Potsdam-Golm, Germany) for introducing I.F. into the micrografting technique.

Conflicts of Interest: The authors declare no conflict of interest. The funders had no role in the design of the study; in the collection, analyses, or interpretation of data; in the writing of the manuscript, or in the decision to publish the results.

\section{References}

1. Kopriva, S. Regulation of sulfate assimilation in arabidopsis and beyond. Ann. Bot. 2006, 97, 479-495. [CrossRef]

2. Takahashi, H.; Kopriva, S.; Giordano, M.; Saito, K.; Hell, R. Sulfur assimilation in photosynthetic organisms: Molecular functions and regulations of transporters and assimilatory enzymes. Annu. Rev. Plant Biol. 2011, 62, 157-184. [CrossRef]

3. Egigolashvili, T.; Kopriva, S. Transporters in plant sulfur metabolism. Front. Plant Sci. 2014, 5, 442. [CrossRef]

4. Takahashi, H. Sulfate transport systems in plants: Functional diversity and molecular mechanisms underlying regulatory coordination. J. Exp. Bot. 2019, 70, 4075-4087. [CrossRef]

5. Cao, M.-J.; Wang, Z.; Wirtz, M.; Hell, R.; Oliver, D.J.; Xiang, C.-B. SULTR3;1 is a chloroplast-localized sulfate transporter in Arabidopsis thaliana. Plant J. 2012, 73, 607-616. [CrossRef] [PubMed]

6. Hell, R.; Wirtz, M. Molecular biology, biochemistry and cellular physiology of cysteine metabolism in Arabidopsis thaliana. Arab. Book 2011, 9, e0154. [CrossRef]

7. Vauclare, P.; Kopriva, S.; Fell, D.; Suter, M.; Sticher, L.; von Ballmoos, P.; Krähenbühl, U.; Camp, R.O.D.; Brunold, C. Flux control of sulphate assimilation in Arabidopsis thaliana: Adenosine 5' -phosphosulphate reductase is more susceptible than ATP sulphurylase to negative control by thiols. Plant J. 2002, 31, 729-740. [CrossRef]

8. Feldman-Salit, A.; Veith, N.; Wirtz, M.; Hell, R.; Kummer, U. Distribution of control in the sulfur assimilation in Arabidopsis thaliana depends on environmental conditions. New Phytol. 2019, 222, 1392-1404. [CrossRef] [PubMed]

9. Bork, C.; Schwenn, J.D.; Hell, R. Isolation and characterization of a gene for assimilatory sulfite reductase from Arabidopsis thaliana. Gene 1998, 212, 147-153. [CrossRef]

10. Speiser, A.; Silbermann, M.; Dong, Y.; Haberland, S.; Uslu, V.V.; Wang, S.; Bangash, S.A.; Reichelt, M.; Meyer, A.J.; Wirtz, M.; et al. sulfur partitioning between glutathione and protein synthesis determines plant growth. Plant Physiol. 2018, 177, 927-937. [CrossRef]

11. Dong, Y.; Silbermann, M.; Speiser, A.; Forieri, I.; Linster, E.; Poschet, G.; Samami, A.A.; Wanatabe, M.; Sticht, C.; Teleman, A.; et al. Sulfur availability regulates plant growth via glucose-TOR signaling. Nat. Commun. 2017, 8, 1-10. [CrossRef] 
12. Khan, M.S.; Haas, F.H.; Samami, A.A.; Gholami, A.M.; Bauer, A.; Fellenberg, K.; Reichelt, M.; Hänsch, R.; Mendel, R.R.; Meyer, A.J.; et al. Sulfite reductase defines a newly discovered bottleneck for assimilatory sulfate reduction and is essential for growth and development in arabidopsis thaliana. Plant Cell 2010, 22, 1216-1231. [CrossRef]

13. Saito, K. Regulation of sulfate transport and synthesis of sulfur-containing amino acids. Curr. Opin. Plant Biol. 2000, 3, 188-195. [CrossRef]

14. Maruyama-Nakashita, A.; Nakamura, Y.; Watanabe-Takahashi, A.; Inoue, E.; Yamaya, T.; Takahashi, H. Identification of a novel cis-acting element conferring sulfur deficiency response in Arabidopsis roots. Plant J. 2005, 42, 305-314. [CrossRef]

15. Aarabi, F.; Naake, T.; Fernie, A.R.; Hoefgen, R. Coordinating sulfur pools under sulfate deprivation. Trends Plant Sci. 2020, 25, 1227-1239. [CrossRef] [PubMed]

16. Hamisch, D.; Randewig, D.; Schliesky, S.; Bräutigam, A.; Weber, A.; Geffers, R.; Herschbach, C.; Rennenberg, H.; Mendel, R.R.; Hänsch, R. Impact of SO 2 on Arabidopsis thaliana transcriptome in wildtype and sulfite oxidase knockout plants analyzed by RNA deep sequencing. New Phytol. 2012, 196, 1074-1085. [CrossRef]

17. Yarmolinsky, D.; Brychkova, G.; Fluhr, R.; Sagi, M. Sulfite reductase protects plants against sulfite toxicity. Plant Physiol. 2013, 161, 725-743. [CrossRef] [PubMed]

18. Koprivova, A.; Suter, M.; den Camp, R.O.; Brunold, C.; Kopriva, S. Regulation of sulfate assimilation by nitrogen in Arabidopsis. Plant Physiol. 2000, 122, 737-746. [CrossRef] [PubMed]

19. Tedesco, S.; Erban, A.; Gupta, S.; Kopka, J.; Fevereiro, P.; Kragler, F.; Pina, A. The impact of metabolic scion-rootstock interactions in different grapevine tissues and phloem exudates. Metabolism 2021, 11, 349. [CrossRef] [PubMed]

20. Ohkubo, Y.; Tanaka, M.; Tabata, R.; Ogawa-Ohnishi, M.; Matsubayashi, Y. Shoot-to-root mobile polypeptides involved in systemic regulation of nitrogen acquisition. Nat. Plants 2017, 3, 17029. [CrossRef]

21. Lough, T.J.; Lucas, W.J. Integrative plant biology: Role of phloem long-distance macromolecular trafficking. Annu. Rev. Plant Biol. 2006, 57, 203-232. [CrossRef] [PubMed]

22. Melnyk, C.W.; Meyerowitz, E.M. Plant grafting. Curr. Biol. 2015, 25, R183-R188. [CrossRef]

23. Batool, S.; Uslu, V.V.; Rajab, H.; Ahmad, N.; Waadt, R.; Geiger, D.; Malagoli, M.; Xiang, C.-B.; Hedrich, R.; Rennenberg, H.; et al. Sulfate is incorporated into cysteine to trigger ABA production and stomatal closure. Plant Cell 2018, 30, 2973-2987. [CrossRef]

24. Malcheska, F.; Ahmad, A.; Batool, S.; Müller, H.M.; Ludwig-Müller, J.; Kreuzwieser, J.; Randewig, D.; Hänsch, R.; Mendel, R.R.; Hell, R.; et al. Drought-enhanced xylem sap sulfate closes stomata by affecting ALMT12 and guard cell ABA synthesis. Plant Physiol. 2017, 174, 798-814. [CrossRef]

25. Ernst, L.; Goodger, J.Q.D.; Alvarez, S.; Marsh, E.L.; Berla, B.; Lockhart, E.; Jung, J.; Li, P.; Bohnert, H.J.; Schachtman, D.P. Sulphate as a xylem-borne chemical signal precedes the expression of ABA biosynthetic genes in maize roots. J. Exp. Bot. 2010, 61, 3395-3405. [CrossRef] [PubMed]

26. Kawashima, C.G.; Matthewman, C.A.; Huang, S.; Lee, B.-R.; Yoshimoto, N.; Koprivova, A.; Somoza, I.R.; Todesco, M.; Rathjen, T.; Saito, K.; et al. Interplay of SLIM1 and miR395 in the regulation of sulfate assimilation in Arabidopsis. Plant J. 2011, 66, 863-876. [CrossRef] [PubMed]

27. Matthewman, C.A.; Kawashima, C.G.; Huska, D.; Csorba, T.; Dalmay, T.; Kopriva, S. miR395 is a general component of the sulfate assimilation regulatory network in Arabidopsis. FEBS Lett. 2012, 586, 3242-3248. [CrossRef]

28. Tan, Q.; Zhang, L.; Grant, J.; Cooper, P.; Tegeder, M. Increased phloem transport of s-methylmethionine positively affects sulfur and nitrogen metabolism and seed development in pea plants. Plant Physiol. 2010, 154, 1886-1896. [CrossRef] [PubMed]

29. Bourgis, F.; Roje, S.; Nuccio, M.L.; Fisher, D.B.; Tarczynski, M.C.; Li, C.; Herschbach, C.; Rennenberg, H.; Pimenta, M.J.; Shen, T.L.; et al. S-methylmethionine plays a major role in phloem sulfur transport and is synthesized by a novel type of methyl-transferase. Plant Cell 1999, 11, 1485-1498. [CrossRef] [PubMed]

30. García, M.J.; Corpas, F.J.; Lucena, C.; Alcántara, E.; Pérez-Vicente, R.; Ángel, M.Z.; Bacaicoa, E.; García-Mina, J.M.; Bauer, P.; Romera, F.J. A shoot fe signaling pathway requiring the OPT3 transporter controls GSNO reductase and ethylene in arabidopsis thaliana roots. Front. Plant Sci. 2018, 9, 1325. [CrossRef]

31. Rudolf, E.; Hüther, P.; Forné, I.; Georgii, E.; Han, Y.; Hell, R.; Wirtz, M.; Imhof, A.; Becker, C.; Durner, J.; et al. GSNOR contributes to demethylation and expression of transposable elements and stress-responsive genes. Antioxidants 2021, 10, 1128. [CrossRef] [PubMed]

32. Huang, X.; Chao, D.-Y.; Koprivova, A.; Danku, J.; Wirtz, M.; Müller, S.; Sandoval, F.J.; Bauwe, H.; Roje, S.; Dilkes, B.; et al. Nuclear localised more sulphur accumulation1 epigenetically regulates sulphur homeostasis in arabidopsis thaliana. PLoS Genet. 2016, 12, e1006298. [CrossRef]

33. Astolfi, S.; Celletti, S.; Vigani, G.; Mimmo, T.; Cesco, S. Interaction between sulfur and iron in plants. Front. Plant Sci. 2021, 12, 670308. [CrossRef]

34. Forieri, I.; Sticht, C.; Reichelt, M.; Gretz, N.; Hawkesford, M.; Malagoli, M.; Wirtz, M.; Hell, R. System analysis of metabolism and the transcriptome in Arabidopsis thaliana roots reveals differential co-regulation upon iron, sulfur and potassium deficiency. Plant Cell Environ. 2016, 40, 95-107. [CrossRef]

35. Buchner, P.; Stuiver, C.E.E.; Westerman, S.; Wirtz, M.; Hell, R.; Hawkesford, M.; De Kok, L.J. Regulation of sulfate uptake and expression of sulfate transporter genes in brassica oleracea as affected by atmospheric $\mathrm{H} 2 \mathrm{~S}$ and pedospheric sulfate nutrition. Plant Physiol. 2004, 136, 3396-3408. [CrossRef] [PubMed] 
36. Lappartient, A.G.; Touraine, B. Glutathione-mediated regulation of ATP sulfurylase activity, SO42-uptake, and oxidative stress response in intact canola roots. Plant Physiol. 1997, 114, 177-183. [CrossRef]

37. Hubberten, H.-M.; Klie, S.; Caldana, C.; Degenkolbe, T.; Willmitzer, L.; Hoefgen, R. Additional role of o-acetylserine as a sulfur status-independent regulator during plant growth. Plant J. 2012, 70, 666-677. [CrossRef]

38. Hubberten, H.M.; Drozd, A.; Tran, B.V.; Hesse, H.; Hoefgen, R. Local and systemic regulation of sulphur homeostasis in roots of Arabidopsis thaliana. Plant J. 2012, 72, 625-635. [CrossRef] [PubMed]

39. Lappartient, A.G.; Vidmar, J.J.; Leustek, T.; Glass, A.D.; Touraine, B. Inter-organ signaling in plants: Regulation of ATP sul-furylase and sulfate transporter genes expression in roots mediated by phloem-translocated compound. Plant J. 1999, 18, 89-95. [CrossRef]

40. Lappartient, A.G.; Touraine, B. Demand-driven control of root ATP sulfurylase activity and SO42-uptake in intact canola (the role of phloem-translocated glutathione). Plant Physiol. 1996, 111, 147-157. [CrossRef] [PubMed]

41. Buchner, P.; Takahashi, H.; Hawkesford, M.J. Plant sulphate transporters: Co-ordination of uptake, intracellular and long-distance transport. J. Exp. Bot. 2004, 55, 1765-1773. [CrossRef]

42. Wirtz, M.; Droux, M.; Hell, R. O-acetylserine (thiol) lyase: An enigmatic enzyme of plant cysteine biosynthesis revisited in Arabidopsis thaliana. J. Exp. Bot. 2004, 55, 1785-1798. [CrossRef]

43. Wirtz, M.; Heeg, C.; Samami, A.A.; Ruppert, T.; Hell, R. Enzymes of cysteine synthesis show extensive and conserved modifications patterns that include $\mathrm{N} \alpha$-terminal acetylation. Amino Acids 2010, 39, 1077-1086. [CrossRef]

44. Wirtz, M.; Hell, R. Functional analysis of the cysteine synthase protein complex from plants: Structural, biochemical and regulatory properties. J. Plant Physiol. 2006, 163, 273-286. [CrossRef] [PubMed]

45. Sun, S.-K.; Xu, X.; Tang, Z.; Tang, Z.; Huang, X.-Y.; Wirtz, M.; Hell, R.; Zhao, F.-J. A molecular switch in sulfur metabolism to reduce arsenic and enrich selenium in rice grain. Nat. Commun. 2021, 12,1-14. [CrossRef]

46. Wirtz, M.; Hell, R. Dominant-negative modification reveals the regulatory function of the multimeric cysteine synthase protein complex in transgenic tobacco. Plant Cell 2007, 19, 625-639. [CrossRef]

47. Wirtz, M.; Beard, K.F.M.; Lee, C.P.; Boltz, A.; Schwarzländer, M.; Fuchs, C.; Meyer, A.J.; Heeg, C.; Sweetlove, L.J.; Ratcliffe, R.G.; et al. Mitochondrial cysteine synthase complex regulates o-acetylserine biosynthesis in plants. J. Biol. Chem. 2012, 287, 27941-27947. [CrossRef]

48. Aroca, A.; Gotor, C.; Romero, L.C. Hydrogen sulfide signaling in plants: Emerging roles of protein persulfidation. Front. Plant Sci. 2018, 9, 1369. [CrossRef]

49. Scuffi, D.; Álvarez, C.; Laspina, N.; Gotor, C.; Lamattina, L.; García-Mata, C. Hydrogen sulfide generated by l-cysteine desulfhydrase acts upstream of nitric oxide to modulate abscisic acid-dependent stomatal closure. Plant Physiol. 2014, 166, 2065-2076. [CrossRef]

50. Gotor, C.; García, I.; Crespo, J.L.; Romero, L.C. Sulfide as a signaling molecule in autophagy. Autophagy $2013,9,609-611$. [CrossRef]

51. Zhang, B.; Pasini, R.; Dan, H.; Joshi, N.; Zhao, Y.; Leustek, T.; Zheng, Z.-L. Aberrant gene expression in the ArabidopsisSULTR1;2mutants suggests a possible regulatory role for this sulfate transporter in response to sulfur nutrient status. Plant $J$. 2013, 77, 185-197. [CrossRef] [PubMed]

52. Rouached, H.; Berthomieu, P.; El Kassis, E.; Cathala, N.; Catherinot, V.; Labesse, G.; Davidian, J.-C.; Fourcroy, P. Structural and functional analysis of the c-terminal STAS (sulfate transporter and anti-sigma antagonist) domain of the arabidopsis thaliana sulfate transporter SULTR1. J. Biol. Chem. 2005, 280, 15976-15983. [CrossRef]

53. Shibagaki, N.; Grossman, A.R. Binding of cysteine synthase to the STAS domain of sulfate transporter and its regulatory con-sequences. J. Biol. Chem. 2010, 285, 25094-25102. [CrossRef] [PubMed]

54. Rouached, H.; Wirtz, M.; Alary, R.; Hell, R.; Arpat, B.; Davidian, J.-C.; Fourcroy, P.; Berthomieu, P. Differential regulation of the expression of two high-affinity sulfate transporters, SULTR1.1 and SULTR1.2, in Arabidopsis. Plant Physiol. 2008, 147, 897-911. [CrossRef] [PubMed]

55. Thieme, C.J.; Rojas-Triana, M.; Stecyk, E.; Schudoma, C.; Zhang, W.; Yang, L.; Miñambres, M.; Walther, D.; Schulze, W.X.; Paz-Ares, J.; et al. Endogenous arabidopsis messenger RNAs transported to distant tissues. Nat. Plants 2015, 1, 15025. [CrossRef] [PubMed]

56. Wirtz, M.; Hell, R. Production of cysteine for bacterial and plant biotechnology: Application of cysteine feedback-insensitive isoforms of serine acetyltransferase. Amino Acids 2003, 24, 195-203. [CrossRef] [PubMed] 